\title{
A new strategy for identification of currant (Ribes nigrum L.) cultivars using RAPD markers
}

\author{
J. Huo ${ }^{1 *}$, G. Yang ${ }^{2 *}$, Y. Zhang ${ }^{3}$ and F. Li ${ }^{3}$ \\ ${ }^{1}$ College of Horticulture, Northeast Agricultural University, Harbin, China \\ ${ }^{2}$ Berries Research Institute, Heilongjiang Academy of Agricultural Sciences, \\ Suiling, Heilongjiang, China \\ ${ }^{3}$ Pomology Research Institute, Academy of Agricultural Sciences of Jilin Province, \\ Gongzhuling, Jilin, China \\ *These authors contributed equally to this study. \\ Corresponding author: J. Huo \\ E-mail: junweihuo@yahoo.com.cn
}

Genet. Mol. Res. 12 (2): 2056-2067 (2013)

Received March 13, 2012

Accepted November 31, 2012

Published June 21, 2013

DOI http://dx.doi.org/10.4238/2013.June.21.1

\begin{abstract}
We developed a new approach using RAPD fingerprints to distinguish 37 currant cultivars from northeastern China based on optimization of RAPD by choosing 11 nucleotide primers and strict screening PCR annealing temperature. We found that the manual cultivar identification diagram (MCID) approach clearly developed fingerprints from 8 different primers that were useful for cultivar identification; a cultivar identification diagram (CID) was readily constructed. This CID allows efficient currant cultivar identification, providing information to separate all the currant cultivars from each other, based on the detail polymorphic bands from the corresponding primers, which were marked in the correct positions on the currant CID. According to the CID, 10 currant cultivars in 5 groups were randomly selected for the referable and workable identification of this strategy. The results proved the workability and efficiency of the MCID method, facilitating the identification of fruit cultivars with DNA markers. This MCID approach will be useful for early identification of seedlings in the nursery industry and protection of cultivar rights.
\end{abstract}

Key words: Currant cultivars; New approach; MCID; RAPD; Fingerprint 


\section{INTRODUCTION}

Currant belongs to the subgenus Ribes of the Ribes L. genus within the Grossulariaceae family. Blackcurrant (Ribes nigrum L.) is grown widely throughout temperate areas of Europe and New Zealand, with an annual production of 160,000 tons in Europe and 185,000 tons globally (Jensen, 2009). The centers of genetic diversity for blackcurrant are situated in northern Scandinavia and Russia, although species are also found in North and South America, Asia, and northwest Africa (Brennan, 1996). The fruit has nutritional value with a very high content of ascorbic acid and other antioxidants (Brennan and Graham, 2009), and its primary commercial use is processing for juice. Blackcurrants are related to European (R. nigrum) and Asian (R. ussuriense) species. The fruits are small, purplish black berries, with a distinctive aroma, and with $35.16 \%$ sugar, $13.5 \%$ acid, $1.75 \%$ protein, and $166.6 \mathrm{mg} / \mathrm{kg}$ vitamins. The vitamin C content of currants is 20 to 30 times that of apple and 3 to 4 times that of strawberry, and the content of anthocyanin is even higher than that in blueberries, which are now widely popular around the world. Accordingly, currant has a high economic value. The fruit can be eaten fresh or processed into fruit juice, jam, or wine, and it can also be used as a high-end food additive. The berries and their products are popular in the European and American markets, where they are considered highly palatable and believed to benefit human metabolism, appetite, and nutrition, along with enhancing detoxification and functions of resistance.

Commercially grown cultivars are vegetatively propagated and therefore clonal, and thus high levels of heterozygosity are likely to exist in newly released currant cultivars. Owing to this, the genetic backgrounds of existing resources and cultivated varieties are quite complex. With the development of modern scientific breeding, the parent materials for currant breeding have been progressively more concentrated on fewer superior varieties or strains, which can produce more varieties selected by humans that have similar agronomic traits and subsequently making them difficult to distinguish. In addition, homonymity and heteronymity are very common problems in the collection and preservation of currant germplasm, as they are bothersome in the collection of germplasm resources and in their utilization in the breeding of new varieties and in the study of genetic background. This has become a very important issue that is frequently encountered and shows the need for a way to ensure the accuracy and purity of currant varieties in scientific research and production. Accurate and rapid identification of currant varieties has become an essential and desirable task for breeders, commercial companies, and researchers. Traditional approaches to currant cultivar identification, such as morphological, palynological, cytological, isozyme, etc., have proven to be limited by limited information, difficult operability, low stability and reproducibility, susceptibility to environmental influences, and the need for extensive observation in mature plants.

DNA-based fingerprinting markers overcome these limitations and can provide a powerful tool for proper characterization of cultivars. In recent years, various DNA molecular markers have been developed and used for the studies on genetic diversity, fingerprinting patterns, and origins of cultivars (Lanham et al., 1995; Lanham and Brennan, 1997; Russell et al., 2011). High levels of genetic diversity occur in woody perennial species as determined from allozyme data (Hamrick and Godt, 1990), and DNA-based molecular markers provide an opportunity for a broader, random sampling of the genome and should prove suitable for investigating heterozygosity.

Among the available markers, random amplified polymorphic DNA (RAPD) markers 
seemed to be very useful in plant cultivar identification analysis with advantages of simplicity, efficiency, relative ease of use, and lack of requirement of any previous sequence information, by using the MCID strategy (manual cultivar identification diagram) (Korir et al., 2012) . To date, RAPD markers have been used in cultivar identification of many fruit species, including fruiting mei (Li et al., 2011), flowering mei (Wang et al., 2011), grape (Lin et al., 2011), lemon (Mu et al., 2012), loose-skin mandarin (Leng et al., 2012), loquat (Zhang et al., 2011), pomegranate (Hasnaoui et al., 2010; Zhang et al., 2012), apricot (Ercisli et al., 2009), banana (Gubbuk et al., 2004), pistachio (Javanshah et al., 2007), and strawberry (Wang et al., 2007), and in genetic variation studies.

Even though DNA markers are advantageous, in practice there is no tight link between the marker information and concrete plant varieties, and the markers have not yet made identification of fruit crop varieties an efficient, recordable, or easy task. The main challenge in this situation are the strategies for analysis of DNA fingerprints, which in turn has made the utilization of DNA markers in crop and seed identification an unpopular practice. The need to develop new strategies for application of new information and technology to practical agricultural activities is therefore both significant and pressing.

Compared to other main fruit crops, currant has not been accorded much attention from geneticists or molecular biologists. The available reports about currant cultivar identification using molecular markers are limited and employed cluster analysis statistical techniques to analyze banding patterns. However, their results were not sufficiently adequate to make cultivar identification easier or more referable, even though they could quantify genetic diversity levels and separate individual plants in the analysis. Developing a strategy that will make optimal use of the advantages of DNA markers for easy identification of currant cultivars is necessary for the currant nursery and production industry. In this study, we employed MCID strategy and successfully identified 37 cultivars of currant using RAPD markers. This process can generate a cultivar identification diagram (CID) presenting the information to be used for the identification of some groups of cultivars. This CID can work like the periodic table of elements and has advantages of relevance, workability, ease of use, and flexibility because additional new cultivars can be added. It is the first strategy that makes currant cultivar identification much more applicable, and efficient, as well as easier and more direct in practice, even though one or more PCRs are required. It will provide valuable information and a reasonable scientific basis for identification of cultivars, genetic diversity, cultivar introduction, and genetic improvement on the molecular level, and it may be essential in securing protection for new varieties through distinctness, uniformity and stability testing (Lu et al., 2009). This new strategy for identification of varieties, parents of hybrids, and specific biodiversity units can be a fundamental tool in preserving intellectual property protection for plant breeders and farmers.

\section{MATERIAL AND METHODS}

\section{Plant materials}

Leaf samples of 37 important currant cultivars (Table 1) were collected from the currant germplasm collection at Northeast Agricultural University, Harbin, P.R. China. The RAPD primers were synthesized by Shanghai Invitrogen Biotechnology Company. 


\begin{tabular}{rlll}
\multicolumn{2}{l}{ Table 1. Cultivar name and origin of currant used in this study. } \\
\hline No. & Cultivar name & No. & \\
\hline 1 & USSURIE & 20 & Cultivar name \\
2 & OIEBYN & 21 & NAEUCZA \\
3 & NEAUHZJ 14 & 22 & NEAUYADE \\
4 & BELYANA & 23 & KRASNIY KREST \\
5 & RESAGER & 24 & NEAUAZA \\
6 & MENDIP CROSS & 25 & BAJILA \\
7 & BEN NEVIS & 26 & BLACKSMITH \\
8 & NEAUJDL & 27 & NEAUWILDHH \\
9 & LIANGYE & 28 & FERTODI \\
10 & NEAUHZJ 17B & 29 & NEAUHZJ 19 \\
11 & GREAT & 30 & BEN LOMOND \\
12 & LAMA & 31 & NESTOR KOZIN \\
13 & BALDWIN & 32 & WANGHJ 16 \\
14 & NEAUBZA & 33 & YADRENAYA \\
15 & PRIMORSKIJ CEMPION & 34 & HANFENG \\
16 & BRODTORP & 35 & HEIFENG \\
17 & NEAUHZJ 17 & 36 & DAISHA \\
18 & ROODKNOP & 37 & NEAUHZJ \\
19 & NEAUBLWZ & & \\
\hline
\end{tabular}

\section{DNA isolation}

Young fresh leaves of 37 cultivars (Table 1) were collected for DNA extraction and flash frozen in liquid nitrogen. Each leaf sample was then ground in liquid nitrogen and the powder was stored at $-40^{\circ} \mathrm{C}$ until use. Genomic DNA was isolated from leaves according to the modified SDS method (Lin et al., 2001) and then purified and checked for quality by electrophoresis on a $0.8 \%$ agarose gel. The concentrations and purity were quantified using a Bio-Photometer (Eppendorf). DNA was diluted to $40-70 \mathrm{ng} / \mu \mathrm{L}$ and stored at $-40^{\circ} \mathrm{C}$ until used.

\section{Gradient screening and primer selection}

Annealing temperature is a key element of conventional PCR techniques, and to ensure high repeatability and stability of RAPD technology, it is essential to perform gradient filtering of annealing temperatures for different primers. PCR was performed according to the method of Yu et al. (2009), and the specific reactions were as follows: $1.5 \mu \mathrm{L} 10 \mathrm{X}$ buffer; 1.2 $\mu \mathrm{L} 2.5 \mathrm{mM}$ dNTPs (Takara Biotechnology, Dalian, Co., Ltd., China), $0.8 \mu \mathrm{L} 25 \mathrm{mM} \mathrm{Mg}^{2+}$; $0.6 \mu \mathrm{L} 10 \mathrm{pmol} / \mu \mathrm{L}$ primer; $1 \mu \mathrm{L} 50 \mathrm{ng} / \mu \mathrm{L}$ template DNA; $0.08 \mu \mathrm{L} 5 \mathrm{U} / \mu \mathrm{L}$ DNA polymerase (Takara Biotechnology); and $\mathrm{ddH}_{2} \mathrm{O}$ to a total volume of $15 \mu \mathrm{L}$. Amplification reactions were performed in an Eppendorf Thermal cycler under the following program: initial denaturation at $94^{\circ} \mathrm{C}$ for $5 \mathrm{~min} ; 40$ cycles with $94^{\circ} \mathrm{C}$ for $30 \mathrm{~s} ; 35^{\circ} \sim 45^{\circ} \mathrm{C}$ for $1 \mathrm{~min} ; 72^{\circ} \mathrm{C}$ for $2 \mathrm{~min}$, and a final temperature of $72^{\circ} \mathrm{C}$ under extension of $10 \mathrm{~min}$. In order to ensure the quality of PCR products, the primers with clear, highly repeated bands were selected according to 3 consecutive gradients, and we chose the higher temperature for the appropriate choice.

\section{RAPD amplification}

The PCR was composed of $2.5 \mu \mathrm{L}$ 10X PCR buffer, $2.5 \mathrm{mM} \mathrm{Mg}^{2+}, 2.5 \mathrm{mM}$ dNTPs, 
2.0 U Taq polymerase, 50-80 ng DNA template, 10 pmol random primers, and $\mathrm{ddH}_{2} \mathrm{O}$ to a final volume of $25 \mu \mathrm{L}$. The amplification reactions were performed following the same steps as mentioned above. Each reaction was repeated 3 times. The amplification products were separated on a $1.3 \%$ agarose gel with $100 \mathrm{mg} / \mathrm{mL}$ ethidium bromide, in $1 \mathrm{X}$ TAE buffer during $1 \mathrm{~h}$ at $100 \mathrm{~V}$ and photographed under UV light.

\section{Statistical analysis}

Clear and unambiguous bands were manually scored from photographic prints of gels for each cultivar. We classified the cultivars into different groups according to the fingerprint amplified by each primer. When cultivars share the same band patterns, they were placed into the same group. More primers were then employed to distinguish the cultivars in each group. The more primers we used, the more specific the amplified bands that were generated, allowing us to differentiate all the cultivars separately. Thereafter, our cultivar identification diagram, comprising bands with specific sizes used to separate the cultivars and all the related primers that generated the specific bands, was constructed for the full division of all the cultivars.

\section{Test of the utilization and workability of the diagram in cultivar identification}

Two groups of cultivars were randomly selected to verify the accuracy of this method. The specific primers that amplified the polymorphic fragments to be used in separating the cultivars were easily found on the diagram. If the cultivars can be distinguished well as anticipated, it would help to assure the workability and efficiency of the approach, not only for the present study, but also for similar study in the future. The PCR was set as described above.

\section{RESULTS}

\section{Optimization of a RAPD technology system of currants}

To establish a stable and reliable RAPD system with high reproducibility, longer primers (11 nucleotides) were employed and the annealing temperatures for each primer were screened based on the quality and reproducibility of banding patterns. These 2 aspects were the key factors influencing the stability of PCR. The primers were randomly screened from a stock of eighty 11-mer primers, and once an optimum primer that could produce clear, reproducible polymorphic bands was screened, it was utilized further in the identification of currant cultivars. The fingerprints from the primers screened were polymorphic and stable, with PCR product size in a range of 200 to $3000 \mathrm{bp}$ (Figure 1), indicating reliability of the optimized RAPD PCR systems and the fingerprints generated.

\section{Cultivar identification}

In cultivar identification description, cultivars with a specific band in the fingerprint generated from 1 primer could be separated singly, and those cultivars sharing the same banding pattern were separated into the same sub-group. In this way, all the currant cultivars were 

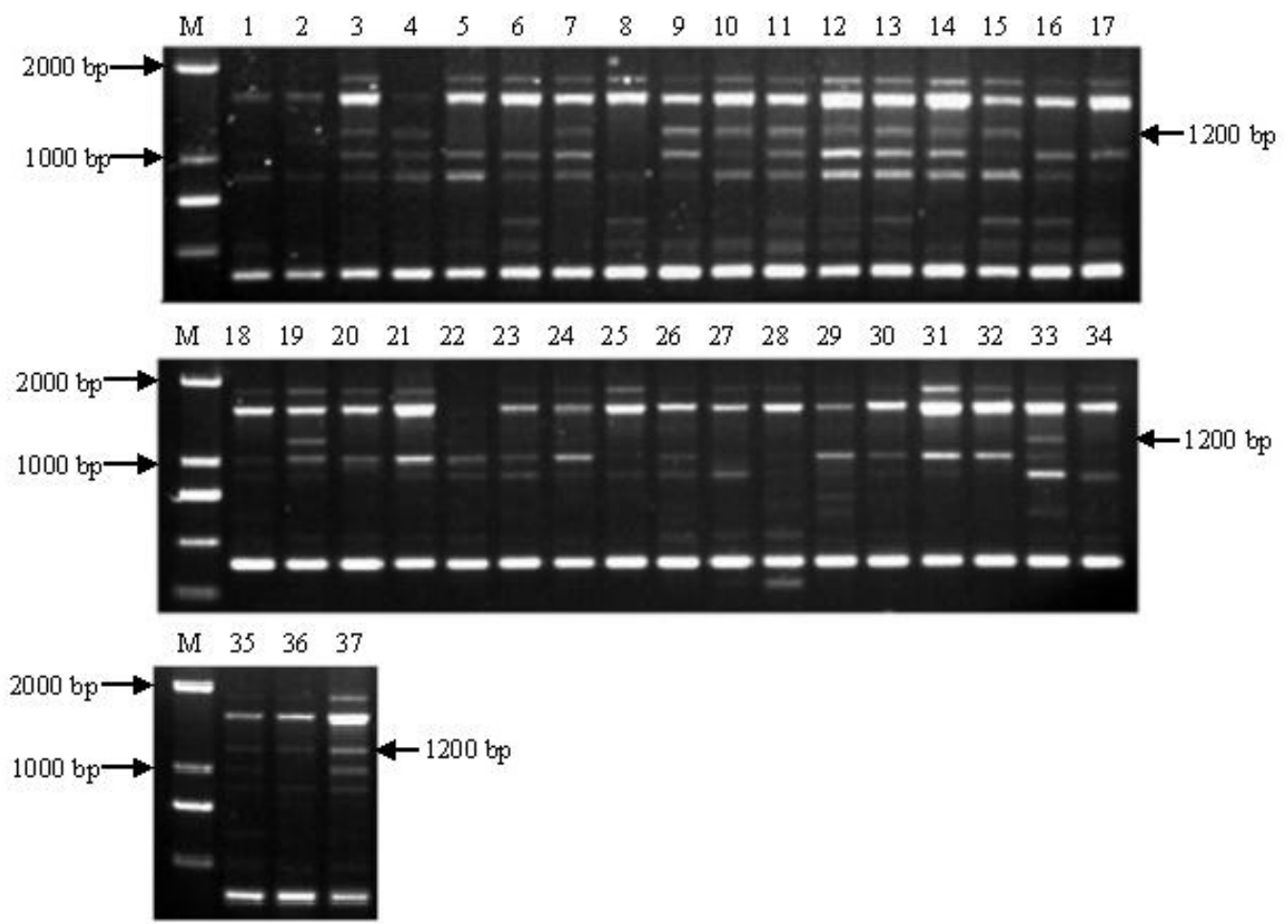

Figure 1. DNA banding patterns of 37 currant cultivars amplified by primer Y34. Lane $M=$ DL2000 plus DNA ladders; lanes 1 to 37 =accession numbers of currant cultivars listed in Table 1 and the same as those in the following Figures.

gradually and completely separated from each other as more primers were employed. After the 8 primers (Table 2) were screened and utilized, all the cultivars were successfully identified. Of the 8 primers used, primer Y34, whose PCR patterns are shown in Figure 1, was the first to be screened and used in the identification of all the 37 cultivars. Polymorphic bands with sizes of $1200 \mathrm{bp}$ were chosen to separate the 37 cultivars, and the presence and/or absence of this band classified the cultivars into 2 groups as shown in the diagram (Figure 1). The first group, including 15 currant cultivars, was separated by the presence of $1200 \mathrm{bp}$, and the other groups contained 22 cultivars missing $1200 \mathrm{bp}$.

Table 2. Summary of primers used in the study.

\begin{tabular}{llr}
\hline Primer No. & Primer $\left(5^{\prime} \rightarrow 3^{\prime}\right)$ & Annealing temperature $\left({ }^{\circ} \mathrm{C}\right)$ \\
\hline Y11 & CTGCTGGGACG & 40.4 \\
Y22 & GGACCCAACCT & 40.4 \\
Y30 & GTGTGCCCCAC & 40.4 \\
Y34 & AAGCCTCGTCT & 44.4 \\
Y41 & AGCGTCCTCCG & 43.7 \\
Y45 & ACGACCGACAA & 44.4 \\
Y48 & ACGACCGACAC & 44.4 \\
Y59 & ACCCCCGACTG & 43.7 \\
\hline
\end{tabular}


The first group was further separated into 2 subgroups with information of the presence and/or absence of $650 \mathrm{bp}$ amplified by primer Y45 (Figure 2). The 2 subgroups were separated into 4 teams by the presence of an 850-bp PCR product amplified via Y48. The 2 cultivars ('BELYANA' and 'GREAT') in the first team were distinguished by the absence of the 300-bp bands amplified by the primer Y41; the 4 cultivars ('BEN NEVIS', 'NEAUBLWZ', 'HEIFENG', 'DAISHA') in the second team were also distinguished by the absence of the 300-bp bands from Y41, and the cultivar named 'DAISHA' was separately identified, while the other 3 cultivars were then further identified by polymorphic bands of 750 and $1200 \mathrm{bp}$ from primers Y59 and Y22, shown as in the diagram (Figure 2). The third team containing 'LAMA', 'BALDWIN', and 'YADRENAYA' was differentiated well by polymorphic bands of 300 and $1000 \mathrm{bp}$ amplified by Y41 and Y11. The cultivar 'LIANGYE' in the fourth team was differentiated well by the polymorphic bands of 300 and $200 \mathrm{bp}$ from Y41; 'PRIMORSKIJ CEMPION' and 'NEAUHZJ' were identified by the presence and/or absence of $300 \mathrm{bp}$ amplified from primer Y11.

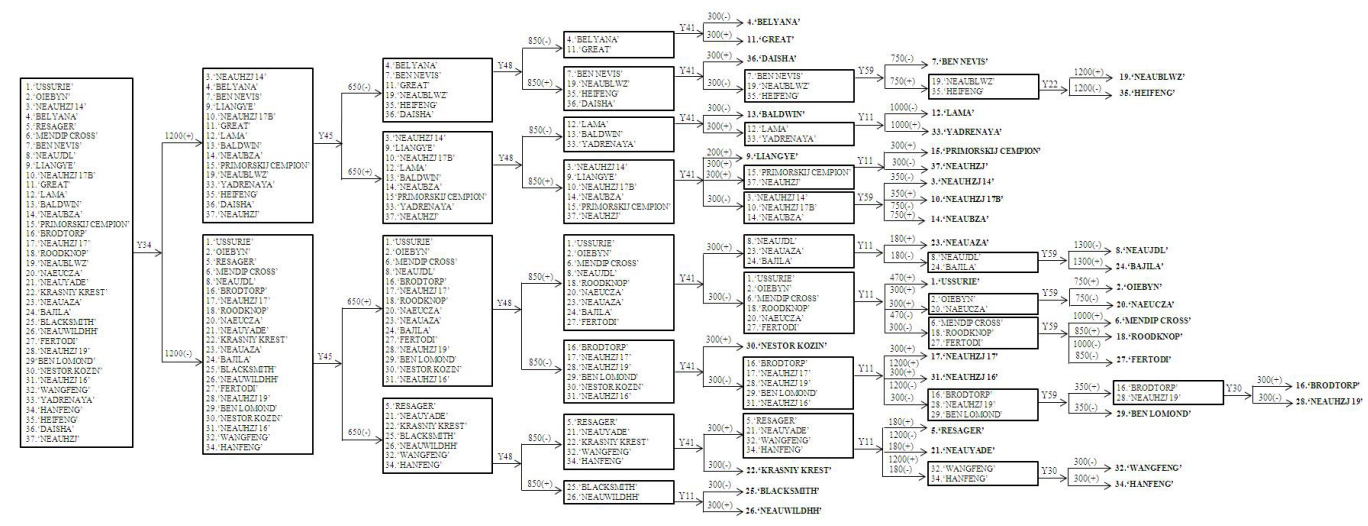

Figure 2. Identification results of currant cultivars used by 8 primers and detail fingerprints. All numbers marked in this chart indicated different size fingerprints, and the unit is "bp"; $(+)=$ presence of bands in different sizes; $(-)$ $=$ absence of bands in different sizes.

The sub-team containing 'NEAUHZJ 14', 'NEAUHZJ 17B', and 'NEAUBZA' were separated by the absence of $300 \mathrm{bp}$ amplified by Y41, then further identified by 2 polymorphic bands of 350 and $750 \mathrm{bp}$ from Y59. Thus, the 15 currant cultivars in the first group were successfully identified. There was a direct connection between the specific bands, primers used, and cultivars identified, which is an important information that can be utilized in identification of these cultivars even in the future. Similarly, the other groups of cultivars from the separation by primer Y 34 were fully separated by several other primers, and the related information is included in Figure 2.

Finally, all 37 of the currant cultivars were successfully identified by the joint use of 8 different primers, and the flow diagram of the amplification patterns would make the identification of each of these 37 cultivars an efficient, relevant, and easy task in the currant industry, as there was a close connection between the specific bands, primers used, and the cultivars identified. Our new technique is another example of the usefulness of DNA markers in plant 
identification. Assay results are more easily readable and recordable than previously reported plant identification methods.

\section{Result verification}

This study aimed to generate a diagram similar to those in cluster analyses of some cultivars, and we sought to ensure that the diagram would be referable and workable in practice for the identification of currant cultivars, which was the original focus of developing the new strategy. According to the results outlined herein, this strategy also has potential to make DNA markers more applicable for fruit plant variety identification. To confirm this, a trial of the diagram in cultivar identification is necessary. A notable example of the technique is where primer Y34 was used to amplify the genomic sequence of the 2 groups of currant varieties of 'NEAUJDL' and 'HEIFENG'; 'NEAUBLWZ' and 'NEAUHZJ 19' (Figure 3A), with the size of the specific band used for cultivar identification being approximately 1200 bp. Because 'NEAUBLWZ' and 'HEIFENG' amplified the specific band that was absent in the other 2 cultivars, these 4 cultivars could be separated. Figure $3 \mathrm{~B}$ shows that 'MENDIP CROSS' and 'HANFENG' could be separated by Y45 with the specific bands of 650 bp while 'ROODKNOP' and 'BEN LOMOND' could be separated by Y48 with 850 bp (Figure 3C); 'USSURIE' and 'OIEBYN' were distinguished by Y11 with the specific band of $470 \mathrm{bp}$, shown in Figure 3D. The verification test confirmed that this method was accurate and reliable and that it can be applied as a scale-like scheme for provision of the information needed for separating cultivars as desired.
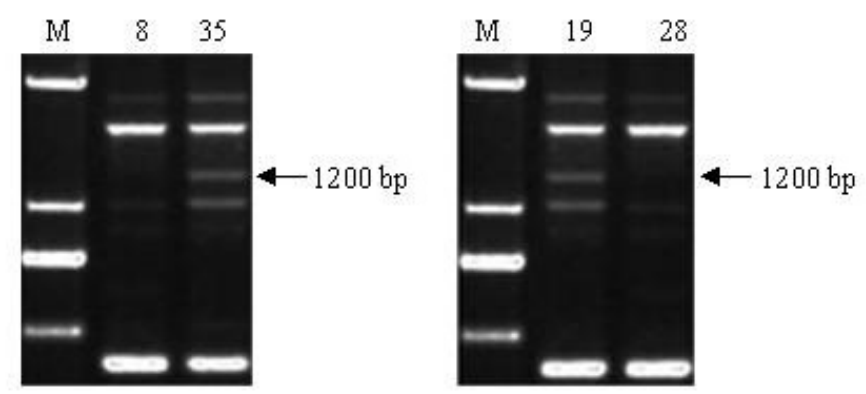

A

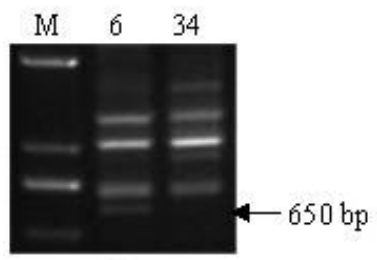

B

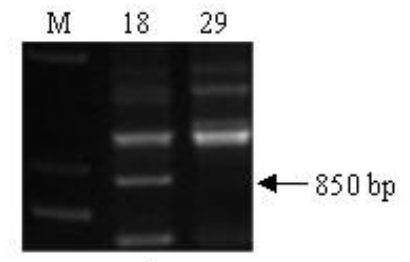

C

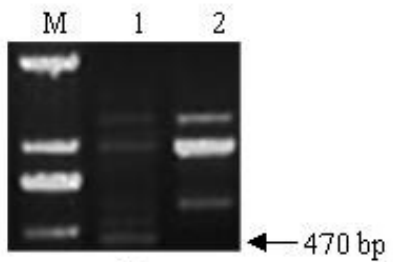

D

Figure 3. Verification result of two cultivars selected randomly by the corresponding primers. Lane M= DL2000 plus marker; other lanes $=$ accession number of the cultivars used as listed in Table 1 . 


\section{DISCUSSION}

The need to develop strategies for applying new information and technology to practical activities is both necessary and pressing. DNA markers are powerful tools that can be used to identify plant cultivars and species, with several generations of DNA markers having been developed and used for cultivar identification (Saker et al., 2006; Chiu et al., 2011) and genetic analysis (Boronnikova et al., 2007; Silvestrini et al., 2008; Bhau et al., 2009; Baysal et al., 2010) so far, and numerous papers published. However, DNA markers have not been easily adapted for genotyping plants. Indeed, the question of whether DNA markers can be readily used in the identification of plant varieties has yielded a negative initial response (Lin et al., 2011). No efficient approach since phylogenetic tree clusters or some fingerprinting has been developed to use DNA markers easily and efficiently for plant cultivar identification, and the clusters formed in the phylogenetic trees cannot tell us which information can be used for the identification of the plant samples desired, while the latter cannot present all the fingerprints of the many cultivars together for the identification. The main reasons for these weakness are that no analysis could connect the information of DNA fingerprints with the cultivars in clear and readable way (Li et al., 2011; Leng et al., 2012). The approach developed in this study uses DNA markers efficiently to distinguish the cultivars as desired. It is a less costly and more timely and objective method, and it harnesses the power of DNA markers for plant cultivar identification using the polymorphic bands of each primer to gradually distinguish every species and individual plant, from which a cultivar identification diagram for further identification of these cultivars can finally be constructed for practical application. This method does not purport to accurately reflect genetic relationships, but theoretically, the first plant to be separated, the farther the genetic distance between it and the others. This strategy offers an efficient, reproducible method for plant cultivar identification by RAPD DNA fingerprinting for protection of cultivar-rights and early identification of seedlings in the nursery industry. To improve the efficiency and application of this strategy in the fruit crop industry, the identification of commercially important cultivars was carried out. When there are one or a few new cultivars that need to be distinguished, with the identification results added to the dynamic diagram, the whole set of primers used to run the additional DNA samples can be used and a larger diagram with the identification information of the new cultivars created (Zhang et al., 2012; Mu et al., 2012). If the set of primers used originally, such as the 8 used in this study, will not work well in the separation of new cultivars, new primers can be used. This study is not time consuming or difficult, and it deserves to be considered for utilization in agriculture.

Currants have been cultivated in China for centuries according to the historical records, and they are widely cultivated in the northeast of China. In terms of economic importance, the crop is mainly used for processing, especially juice production, where the high levels

of ascorbic acid and anthocyanins are valued (Brennan et al., 2008). For better development of currant research and industry, identification of currant cultivars and germplasm resources is indispensable. Therefore, this study could be of considerable help in promoting genetic resource conservation and utilization as well as plant variety protection. The development and potential use of molecular markers in currant and related Ribes species has been previously reported, using inter-simple sequence repeats (Lanham et al., 2000), AFLPs (Lanham and Brennan, 1999) and microsatellites (SSRs) (Brennan et al., 2002), and SNP (Russell et al., 2011). However, no efficient strategy to apply DNA markers easily for currant variety identification had been 
reported. The major aim of this study was not only to demonstrate how to use RAPD markers to distinguish the 37 currant cultivars using the principle of DNA fingerprints for identifying plant cultivars, but to also develop a new strategy to properly utilize DNA markers for the separation of cultivars that could also be considered as a universal strategy for distinguishing other plant and seed samples. The optimized RAPD may be a preferred technique to make this strategy more efficient and easier to adapt.

Another distinctive result of our demonstration of this strategy is that a readable and referable cultivar identification diagram can be constructed for use in the identification of the related plant species in a manner similar to the use of the periodic table of elements, i.e., in providing the basic information of each cultivar in a central, universally accessible fashion. This method could be of great help in the nursery industry and provide valuable information for cultivar-rights protection.

This strategy can also improve the efficiency of plant identification because few primers and PCRs are needed, and polymorphic bands can be utilized suitably, while the DNA fingerprints from various primers can be jointly utilized for a more thorough identification. In this study, 8 RAPD primers were adequate to distinguish all 37 currant cultivars evaluated, providing a diagrammatic representation for future reference in currant cultivar identification. Verification of the accuracy of the cultivar identification and the workability of the diagram indicated the potential for practical cultivar identification, for which all the groups of cultivars distinguished are identified using the specific primers as anticipated. The present study offers a new method for accurate and reliable identification of currant varieties, and in turn offers a good theoretical foundation for a tool to identify new cultivars and protect intellectual property rights (Wang et al., 2009).

The notion that DNA markers are not easily used in practical plant separation is overcome by this strategy, because most of our results generated from work using DNA markers were not practically referable or workable for future use, until our strategy demonstrated how to make the markers more applicable for varietal identification. This study marks the beginning of a project to present all of the identification information of most fruit crop cultivars cultivated in China for cultivar-rights protection and assistance to the nursery industry. We recommend our strategy as an ideal application of DNA markers for the identification of plants, seed samples, and animals. All of the identification results can also be used to generate informative tables for wider use in silico.

\section{ACKNOWLEDGMENTS}

Research supported by the Special Research Projects Fund of the Ministry of Agriculture Industry (\#nyhyzx07-028).

\section{REFERENCES}

Baysal Ö, Siragusa M, Gumrukcu E, Zengin S, et al. (2010). Molecular characterization of Fusarium oxysporum $\mathrm{f}$. melongenae by ISSR and RAPD markers on eggplant. Biochem. Genet. 48: 524-537.

Bhau BS, Medhi K, Das AP, Saikia SP, et al. (2009). Analysis of genetic diversity of Persea bombycina "Som" using RAPD-based molecular markers. Biochem. Genet. 47: 486-497.

Boronnikova SV, Kokaeva ZG, Gostimsky SA, Dribnokhodova OP, et al. (2007). Analysis of DNA polymorphism in a relict Uralian species, large-flowered foxglove (Digitalis grandiflora Mill.), using RAPD and ISSR markers. Russ. 
J. Genet. 43: 530-535.

Brennan R, Jorgensen L, Woodhead M and Russell J (2002). Development and characterisation of SSR markers in Ribes species. Mol. Ecol. Notes 2: 327-330.

Brennan R, Jorgensen L, Hackett C, Woodhead M, et al. (2008). The development of a genetic linkage map of blackcurrant (Ribes nigrum L.) and the identification of regions associated with key fruit quality and agronomic traits. Euphytica 161: 19-34.

Brennan RM (1996). Currants and Gooseberries. In: Fruit Breeding Volume II: Vine and Small Fruits Crops (Janick J and Moore JN, eds.). John Wiley, New York, 191-295.

Brennan RM and Graham J (2009). Improving fruit quality in Rubus and Ribes through breeding. Funct. Plant Sci. Biotechnol. 3: 22-29.

Chiu T, Pang J, Chen M and Tsen H (2011). Improvement of strain discrimination by combination of RAPD with PFGE for the analysis of the swine isolates of Salmonella enterica serovar Choleraesuis. World J. Microbiol. Biotechnol. 27: 465-469.

Ercisli E, Agar G, Yildrim N, Esitken A, et al. (2009). Identification of apricot cultivars in Turkey (Prunus armeniaca L.) using RAPD markers. Rom. Biotechnol. Lett. 14: 4582-4588.

Gubbuk H, Pekmezci M, Onus AN and Erkan M (2004). Identification and selection of superior banana phenotypes in the cultivar dwarf Cavendish using agronomic characteristics and RAPD markers. Pak. J. Bot. 36: 331-342.

Hamrick JL and Godt MJW (1990). Allozyme Diversity in Plant Species. Plant Population Genetics, Breeding, and Genetic Resources. Sinauer Press, Sunderland, 43-63.

Hasnaoui N, Mars M, Chibani J and Trifi M (2010). Molecular polymorphisms in tunisian pomegranate (Punica granatum L.) as revealed by RAPD fingerprints. Diversity 2: 107-114.

Javanshah A, Tajabadipour A and Mirzaei S (2007). Identification of a new phenotype (Siah Barg) of pistachio (Pistacia vera L.) with shiny-blackish green leaves using RAPD assay. Int. J. Agric. Biol. 9: 307-310.

Jensen S (2009). Judgement on the Harvest of the Year. Proceedings of the 15th European Blackcurrant Conference, Nyborg, Denmark. Available at [http://www.gartneriraadgivningen.dk/Nyheder/Solbaer/Presentations/Presentations.html].

Korir NK, Han J, Shangguan L, Wang C, et al. (2012). Plant variety and cultivar identification: advances and prospects. Crit. Rev. Biotechnol.

Lanham PG and Brennan RM (1997). Characterization of the genetic resources of redcurrant (Ribes rubrum: subg. Ribesia) using anchored microsatellite markers. Theor. Appl. Genet. 96: 917-921.

Lanham PG and Brennan RM (1999). Genetic characterization of gooseberry (Ribes grossularia subgenus grossularia) germplasm using RAPD, ISSR and AFLP markers. J. Hort. Sci. Biotechnol. 74: 361-366.

Lanham PG, Brennan RM, Hackett C and McNicol RJ (1995). RAPD fingerprinting of blackcurrant (Ribes nigrum L.) cultivars. Theor. Appl. Genet. 90: 166-172.

Lanham PG, Korycinska A and Brennan RM (2000). Genetic diversity within a secondary gene pool for Ribes nigrum L. revealed by RAPD and ISSR markers. J. Hort. Sci. Biotechnol. 75: 371-375.

Leng XP, Li HR, Zhong GY, Song CN, et al. (2012). Employment of a new strategy for identification of loose-skin mandarin (Citrus reticulata Blanco) cultivars using RAPD markers. Rom. Biotechnol. Lett. 17: 7073-7083.

Li XY, Wang C, Yang G, Li XD, et al. (2011). Employment of a new strategy for identification of Prunus mume cultivars using random amplified polymorphic deoxyribonucleic acid (RAPD) markers. Afr. J. Plant Sci. 5: 500-509.

Lin J, Wang XC, Chang YH and Fang JG (2011). Development of a novel and efficient strategy for practical identification of Pyrus spp (Rosaceae) cultivars using RAPD fingerprints. Genet. Mol. Res. 10: 932-942.

Lin RC, Ding ZS, Li LB and Kuang TY (2001). A rapid and efficient DNA minipreparation suitable for screening transgenic plants. Plant Mol. Biol. Rep. 19: 379.

Lu X, Lu X, Gong Y, Zhao L, et al. (2009). Cultivar identification and genetic diversity analysis of broccoli and its related species with RAPD and ISSR markers. Sci. Hortic. 122: 645-648.

Mu Q, Sun X, Zhong G, Wang X, et al. (2012). Employment of a new strategy for identification of lemon (Citrus limon L.) cultivars using RAPD markers. Afr. J. Agr. Res. 7: 2075-2082.

Russell JR, Bayer M, Booth C, Cardle L, et al. (2011). Identification, utilisation and mapping of novel transcriptome-based markers from blackcurrant (Ribes nigrum). BMC Plant Biol. 11: 147.

Saker MM, Adawy SS, Mohamed AA and El-itriby HA (2006). Monitoring of cultivar identity in tissue culture-derived date palms using RAPD and AFLP analysis. Biol. Plant. 50: 198-204.

Silvestrini M, Maluf MP, Silvarolla MB, Guerreiro-Filho O, et al. (2008). Genetic diversity of a Coffea germplasm collection assessed by RAPD markers. Genet. Resour. Crop Evol. 55: 901-910.

Wang C, Fang J, Zhang Z, Cao S, et al. (2009). Brief introduction of fruit cultivar-right-protection in China and its ongoing situation. Chin. Agric. Sci. Bull. 25: 298-302.

Wang YJ, Li XY, Han J, Fang WM, et al. (2011). Analysis of genetic relationships and identification of 54 flowering-mei 
cultivars using EST-SSR markers developed from apricot and fruiting mei. Sci. Hortic. 132: 12-17.

Wang Z, Zhang Z, Li H, Gao X, et al. (2007). Identification of strawberry cultivars by RAPD and SCAR markers. Acta Hortic. Sin. 34: 591-596.

Yu H, Fang J, Zhang M, Yang G, et al. (2009). Study on application of RAPD marker in cultivar identification of seven fruit crops. Acta Agric. Jiangxi 21: 5-9.

Zhang X, Qian J, Wang H, Yuan W, et al. (2011). A novel strategy employed in identification of 25 important loquat cultivars using RAPD marker. Caryologia 64: 265-271.

Zhang Y, Tan H, Wang X, Yang G, et al. (2012). A novel strategy for identification of 47 pomegranate (Punica granatum L.) cultivars using RAPD markers. Genet. Mol. Res. DOI http://dx.doi.org/10.4238/2012.May.30.1. 